\title{
Histological and Immunohistochemical Study of The Effect of Cyclophosphamide on Testis of Male Adult Albino Rats and The Possible Protective Role of Vitamin E Gamal S. El Gharabawy, Ezz El-Dein E. Abd Allah, Ibrahim M. Amr, Mohammed Elmitwalli* \\ Histology Department - Faculty of Medicine, Al-Azhar University \\ *Corresponding author: Mohammed Elmitwalli, Mobile: +20- 01094972119
}

\begin{abstract}
Background: cyclophosphamide is not only used as anticancer chemotherapeutic drug in adult and childhood malignancies, but also used as an immunosuppressive agent for organ transplantation. Aim of the work: this work was planned to evaluate the histological, immunohistochemical and ultrastractural changes in the testis of adult male Albino rats after administration of cyclophosamide and the possible role of vitamin E supplementation and drug withdrawal were explored.

Materials and Methods: 50 healthy male Albino rats weighted 200gm were categorized into 5 groups, (ten rats each group). At the end of the experiment, the animals of all groups were anaesthetized by ether inhalation. Their testes were dissected out carefully and processed for light and electron microscope examination. The testes were immediately dissected out and the samples for light microscope were fixed in $10 \%$ neutral buffered formaldehyde ( $\mathrm{pH}$ 7.2) for 24-72 hours. Sections (5um thick) were obtained and stained with H\&E, Mallory's trichrome, PAS stains and immunohistochemicaly for detecting bcl-2 protein were used. Minute specimens were double fixed in glutaraldehyde and processed to obtain semithin sections stained with toluidine blue and ultrathin sections (70nm) for TEM.

Results: testes of the cyclophosphamide-treated adult rats and cyclophosphamide withdrawal group revealed thick tunica albuginea, distorted and shrunken seminiferous tubules with wide interstitium in between. These tubules had marked reduction in the thickness of the germinal epithelium which appeared detached from irregular thick basement membrane and wide empty lumina were devoid of spermatozoa. The germinal epithelium in these tubules appeared degenerated with vacuolated cytoplasm and pyknotic nucle; the interstitium showed acidophilic hyaline material, congested thickened blood vessels and numerous interstitial Leydig cells with pyknotic nuclei. Cross sections of the middle and principle pieces of sperms showed disturbed axoneme. Cross sections in the sperms detected the middle, principle and end pieces. In the middle pieces, the axoneme was surrounded by fibrous and abnormal mitochondrial sheaths. The mitochondria in their sheath showed mild swelling, vacuolization and distortion. Leydig cells had large oval euchromatic nuclei with widened perinuclear space. The cytoplasm contained numerous mitochondria and dilated SER. using vitamin E with cyclophosphamide relatively improved the testicular tissue.

Conclusions: cyclophosphamide treatment produced marked changes in the histological structure of the testes especially the germinal epithelium and sperms. This may lead to serious problems such as infertility or even sterility. The histological affection of cyclophosphamide on testis persisted after stoppage of treatment which is an indication of its cumulative effect. Supplementation of vitamin E with cyclophosphamide relatively improved the testicular tissue. So, administration of vitamin $\mathrm{E}$ in patient received cyclophosphamide is mandatory to reduce its side effects. Keywords: histological, immunohistochemical, clophosphamide, Albino,testis, ultrastructure.
\end{abstract}

\section{INTRODUCTION}

Infertility is one of the most common public health problems that occur as a result of disturbance of spermatogenic process. This process (spermatogenesis) is characterized by complex sequential stages of differentiation, chromosomal assortment and chromatin remolding. The male germ cells are highly susceptible to genotoxicants. Some of these toxic agents cause alteration of spermatogonia with consequent decreased production of spermatozoa. However, the others are quite toxic to cells of the spermatogenic lineage causing death of those cells and sterility (1). Cyclophosphamide (CP) is a class of oxazaphosphorines. It is considered as an important component of many drug regimens. It is not only used as anticancer chemotherapeutic drug in adult and childhood malignancies, but also used as an immunosuppressive agent for organ transplantation. Also, it is used for treatment of many acute and chronic benign diseases such as nephritic syndrome, multiple sclerosis and systemic lupus erythromatosis ${ }^{(2)}$. The same authors added that CP is effectively maintained remission of nephritic syndrome in patients who are resistant to steroid and have frequent relapses. Emadi et al. (3) reported that $\mathrm{CP}$ is an alkylating agent and nitrogen mustard family of medications and works by interfering with the duplication of DNA and the creation of RNA. First, CP in the liver is metabolized to 4-hydroxycyclophosphamide by cytochrome $\mathrm{P} 450$ and then enters into cells and spontaneously degrades to phosphoramide-mustard and acrolein $^{(4)}$. Phosphoramide-mustard alkylates DNA through alkyl groups is attaching to DNA and prevents its replication and inhibits tumor cells growth. However, acrolein exerts toxic effects on the body's healthy cell because it produces (ROS) and nitric oxide and leads to production of peroxynitrite that destroys intracellular proteins, lipids and DNA ${ }^{(5)}$. 
Ghosh et al. ${ }^{\left({ }^{(6)}\right.}$ mentioned that the testicular tissue is highly susceptible to oxidative stress because testicular membranes are highly rich in polyunsaturated fatty acid. Moreover, the oxidative damage to this poly-unsaturated fatty acid of the cell membrane lead ton impairment of membrane fluidity and permeability. Furthermore, oxidative stress plays a critical role in the pathogenesis of male reproductive toxicity induced by $\mathrm{CP}{ }^{(7)}$. CP produces a high level of active free radicals and reactive oxygen species (ROS) and thus may be lead to spermatogenesis dysfunction or even to sperm's death. Clinical evidence proved that oxidative stress is associated with administration of $\mathrm{CP}$ ${ }^{(8)}$. The presence of rich polyunsaturated fatty acids in the mitochondrial membrane of sperm and low amounts of antioxidants makes sperm more susceptible to lipid peroxidation ${ }^{(9)}$.Antioxidants are able to inhibit oxygen free radicals, reduce oxidative stress and minimize associated complications ${ }^{(\mathbf{1 0})}$. They added that there is a matching system called the antioxidant defense system in the body. It can maintain a steady state of the body and prevents the oxidative damage. This system contains enzymatic and non enzymatic antioxidants. The intracellular concentrations of antioxidants are within range that maintains the antioxidant defense. These protective mechanisms do not act independently of one another, but rather tend to function cooperatively in the form of cascade. The free radicals are produced as byproducts of normal cellular metabolism. When the production of these free radicals exceeds the body's natural antioxidant defense mechanism, the oxidative stress occurs ${ }^{(11)}$.

Das et al. ${ }^{(12)}$ stated the vitamin E (tocopherol) is a fat soluble antioxidant that naturally occurring in wheat, germ oil, green vegetables, eggs, meat, nuts and bananas. It acts as antioxidant by detoxifying the free radicals. Because of its antioxidant properties, vitamin E helps in prevention of numerous diseases associated with oxidative stress. This vitamin resides mainly in the cell membrane of testis and other organ. It interrupts the chain reaction involved in lipid peroxidation and scavenges the reactive oxygen species generated during univalent reduction of molecular oxygen. So, it can protect from oxidative stress.

\section{AIM OF THE WORK}

This study aimed to detect the histological, immunohistochemical and ultrastractural changes in the testes of adult male Albino rats after administration of cyclophosamide. Moreover, the possible role of vitamin E supplementation and drug withdrawal were explored.

\section{MATERIAL AND METHODS \\ Chemicals:}

Endoxan is the trade name of cyclophosphamide produced by Baxter Oncology $\mathrm{GmbH}$ in Frankfurt, Germany. Endoxan 1g contains $1.069 \mathrm{~g}$ cyclophosphamide monohydrate (equivalent to $1 \mathrm{~g}$ anhydrous cyclophosphamide) as the active ingredient. It is a wettable form of white dry powder. In the current work cyclophosphamide was dissolved in distilled water and given orally through gavage. Vitamin E (dialpha-tocopheryl acetate) is available in the form of soft gelatin capsule. Each capsule contains $1000 \mathrm{mg}$ of vitamin E. It was dissolved in oil and given orally through gavage.

\section{Animals:}

A total number of 50 adult male Albino rats were used in this study. Rats were categorized into five groups (ten rats each group). Group I (control) rats were given 0.9 saline orally for the 28 days. Group II (adult Albino rat were supplemented with vitamin E) rats were given vitamin E $200 \mathrm{mg} / \mathrm{kg}$ orally for successive 28 days. Group III (cyclophosphamide treated group) rats were given cyclophosphamide $(5 \mathrm{mg} / \mathrm{kg})$ orally for 28 days. Group IV (cyclophosphamide and vitamin E co-administered group) rats were given cyclophosphamide $\quad(5 \mathrm{mg} / \mathrm{kg})$ concomitantly with vitamin E $(200 \mathrm{mg} / \mathrm{kg})$ orally for the same period of time to assess the role of vitamin $\mathrm{E}$ supplementation. Group V (cyclophosphamide withdrawal group) rats were sacrificed after 28 days from the last dose of cyclophosphamide. At the end of the experiment, the animals of all groups were anaesthetized by ether inhalation. Their testes were dissected out carefully and processed for light and electron microscope examination. The testes were immediately dissected out and the samples for light microscope were fixed in $10 \%$ neutral buffered formaldehyde ( $\mathrm{pH} 7.2$ ) for $24-72$ hours. Sections (5um thick) were obtained and stained with H\&E, Mallory's trichrome, PAS stains and immunohistochemicaly for localization of bcl-2 protein. Minute specimens were double fixed in glutaraldehyde and processed to obtain semithin sections $(1 \mu \mathrm{m}$ thick) stained with toluidine blue and ultrathin sections $(70 \mathrm{~nm})$ for TEM.

\section{Image analysis and morphometric study:}

Stained sections with H\&E, MalIory's trichrome and immunohistochemical reaction were morphometrically analyzed using image analyzer computer system to detect the significance of changes in the diagonal diameters, epithelial height of the seminiferous tubules, area $\%$ of collagen fibers, area $\%$ and optical density for bcl-2.Morphometric study was done in Histology Department Faculty of Medicine in Al Azhar University (Cairo), the software used on the stained sections using image analyzer program optima's version 3.1, the image analyzer was first calibrated to convert the measurement unit produced by the image analyzer program (pixels) into actual micrometer units.

\section{Statistical analysis}

The data checked (the diameter of seminiferous tubules, the epithelial height, area\% of collagen, area\% and optical density) entered and analyzed by using SPSS version 23. 
The data were expressed as means and slandered deviation (SD).The data obtained by image analyzer were analyzed statistically using one-way analysis of variance (ANOVA) for comparison between the different groups (more than two groups) with $\mathrm{p}$ value less than 0.05 (the level of significance).Also, $t$ test and post Hoc Tukey test were used when appropiate. T test was used to compare the control with other groups. Post Hoc Tukey test was used to find the statistical difference between the groups when ANOVA was statistically significant ( $\mathrm{P}$ value $<0.05$ was considered statistically significant).

\section{RESULTS}

Hematoxylin and eosin stained cross sections of testes of group I and II (figs.1a,1 1b, 2a, 2b) showed the same results. The testis was surrounded by tunica albuginea and underlying tunica vasculosa. The testis is consisted of packed regular seminiferous tubules separated by narrow interstitial tissue which contained Leydig cells and blood vessels. The seminiferous tubules were surrounded by regular thin basement membrane and one layer of myoid cells. This tubules were lined by stratified spermatogenic cells and Sertoli cells Spermatogenic cells included: spermatogonia, primary spermatocytes, spermatids and spermatozoa. Cyclophosamide administered group (group III) (figs.1c \&2c) showed marked affection compared to the control group.

There were thick tunica albuginea, distorted and shrunken seminiferous tubules with wide interstitium in between. These tubules had marked reduction in the thickness of the germinal epithelium which and detached from irregular thick basement membrane with wide empty lumina devoid from spermatozoa. The germinal epithelium in these tubules appeared degenerated with vacuolated cytoplasm and pyknotic nuclei. Most of the lining cells of these tubules were sloughed in the lumen and replaced by extremely large intercellular spaces. Many giant cells in mitosis were detected among the other germ cells. The interstitium showed acidophilic hyaline material, congested thickened blood vessels and numerous interstitial Leydig cells with pyknotic nuclei. Cyclophosphamide and vitamin E co-administered (group IV) (figs.1d\&2d) showed significant improvement in the histological structure of the testis. The thickness of the tunica albuginea was significantly decreased compared to group III (cyclophosamide treated rats).

The majority of the tubules were rounded or oval in shape and separated by relatively narrow interstitial spaces.The histological architecture of them was more or less similar to rats of the control group I and revealed remarkable preservation of the germinal epithelium and sperm tails in their lumina. Few degenerated cells, few cells with pyknotic nuclei and few intercellular spaces were realized. These tubules were lined by different types of germ cells, most of these cells had pale rounded nuclei with acidophilic cytoplasm. Also, Sertoli cells exhibited oval pale nuclei situated near the basement membrane and myoid cells nuclei were seen. Most Leydigcells showed open face nuclei with prominent nucleoli and acidophilic cytoplasm while, few cells showed condensed nuclei. Interstitial spaces showed few amount of acidophilic hyaline material and the blood vessels were still congested. Cyclophosphamide withdrawal rats (group V) (figs.1e\&2e) were similar to group III (cyclophosphamide treated rats).

In addition, some tubules showed spermatozoa with cytoplasmic droplets that were shed in the lumen of seminiferous tubules, displaced Sertoli cell and Sertoli cell with vacuolated cytoplasm. 


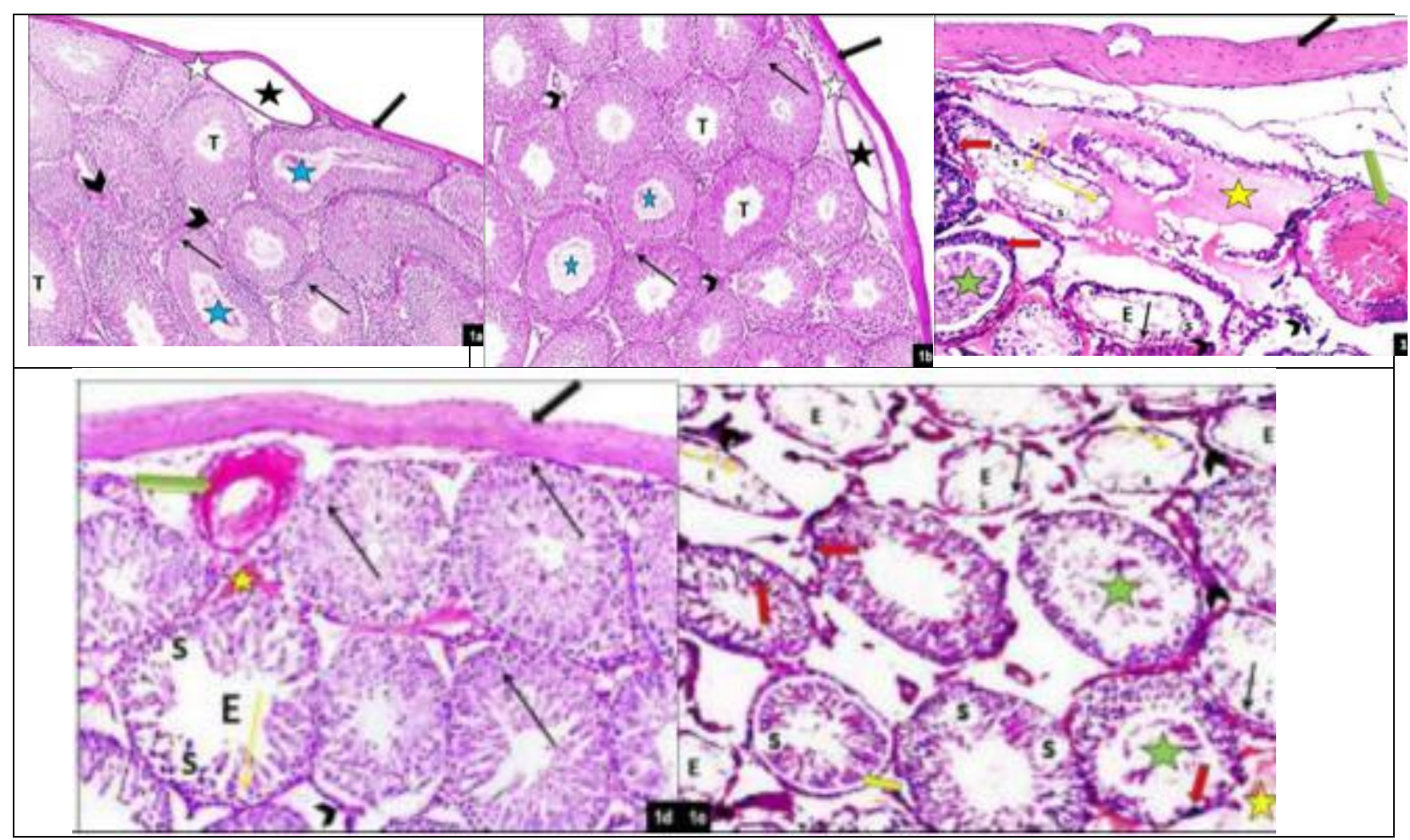

Fig. 1. Photomicrographs of H\&E stained sections of testis of the control group (a) and vitamin $\mathrm{E}$ treated group (b) showing outer tunica albuginea (thick black arrow ) and inner tunica vasculosa (white star) that contain blood vessels (black star). The testicular parenchyma is composed of packed, well organized oval or round seminiferous tubules $(\mathrm{T})$ and separated by narrow interstitium (black arrow heads).

These tubules are lined by layers of stratified germinal epithelium including spermatogenic cells (thin black arrows). Spermatozoa (blue star) are seen in the lumen of some tubules. Cp treated group (c) and $\mathrm{Cp}$ withdrwal group (e) show thick tunica albuginea (thick black arrow) in fig.c,the seminiferous tubules are distorted, shrunken and show marked reduction in the thickness of the germinal epithelium (thin black arrow) and wide empty lumina (E) devoid of spermatozoa. These tubules are lined by few layers of extremely degenerated cells with pyknotic nuclei (red arrow) and vacuolated cytoplasm (yellow arrow) with wide separation between the cells (S).Some tubules show sloughed germinal cells in the lumen (green star).Note the presence of cluster of Leydig cells with pyknotic nuclei (black arrow head).Hyalinization (yellow star) and congested blood vessel with thick wall (green arrow) in the wide interstitial space can be also observed. Cp and vitamin E treated group (d) show moderately thick tunica albuginea (thick black arrow).Most of the tubules show remarkable preservation of the germinal epithelium (thin black arrows).Few tubules are relatively corrugated, distorted with wide empty lumens (E) with few degenerated cells (yellow arrow) and few intercellular spaces (S).The tubules are separated by interstitial tissue which contain Leydig cells (black arrow head), few hyalinization (yellow star) and a congested blood vessel (green arrow). (H\&E X100). 


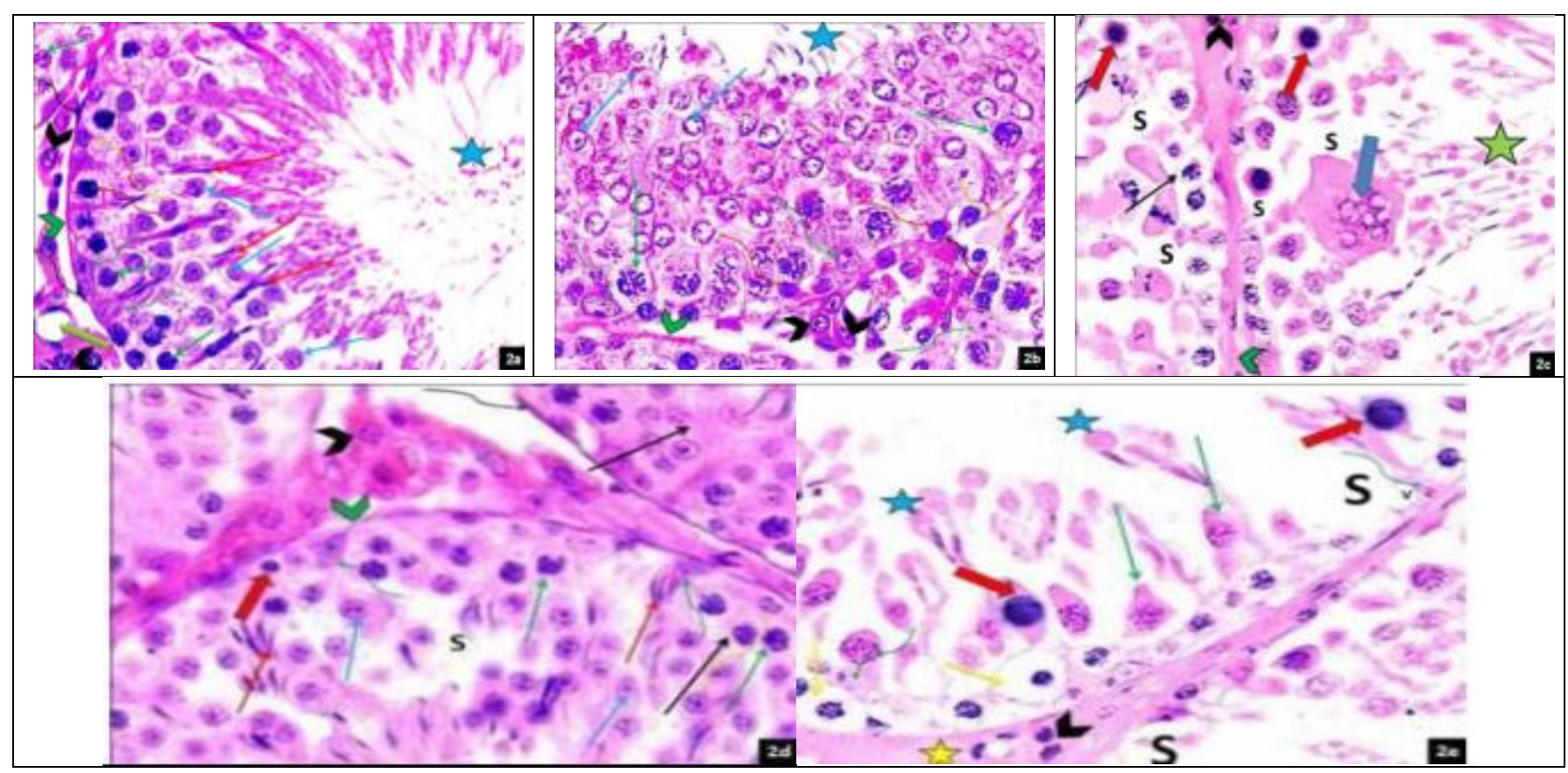

Fig.2. Photomicrographs of H\&E stained sections of testes of the control group (a) and vitamin E treated group (b) showing seminiferous tubules surrounded by myoid cells with flattened nuclei (black zigzag arrows); they are lined with Sertoli cell and spermatogenic cells including pale type A spermatogonia (yellow zigzag arrow) with small pale round nuclei, dark type A spermatogonia (red zigzag arrow) with dark nuclei, primary spermatocytes (thin green arrows) with large rounded nucleus which show reticular network of chromatin, round spermatids with small rounded pale nuclei (blue arrows), elongated spermatids are exhibiting elongated dark nuclei (red arrows) and spermatozoa in the lumen (blue star).Sertoli cell (green zigzag arrow)shows oval pale nucleus and prominent nucleolus near the basement membrane (green arrow head).Interstitial tissue contains a blood vessel (thick green arrow) and Leydig cells with acidophilic cytoplasm and rounded vesicular nuclei (black arrow heads). $\mathrm{Cp}$ treated group (c) and $\mathrm{Cp}$ withdrwal group (e) showing marked thinning of the germinal epithelium (black arrow).Germ cells detached from the thick and irregular basement membrane (green arrow hesd) and replaced by spaces (S) in the epithelium.Notice Multinucleated giant cell (blue arrow) in fig.(c), primary spermatocytes with darkly stained nuclei (red arrows). Shedding of germ cell in the lumen (green star), few sperms and spermatids are observed. Spermatozoa with cytoplasmic droplets are shed in the lumen of seminiferous tubules (blue star), displaced Sertoli cell (yellow zigzag arrow) and Sertoli cell (yellow zigzag arrow) with vacuolated cytoplasm (V) are visible in fig.(e).The interstitial cells of Leydig with pyknotic nuclei can be also seen (arrow head).Cp and vitamin $E$ treated group (d) showing seminiferous tubule with remarkable preservation of the germinal epithelium (black arrow).Spermatogonia (yellow zigzag arrow), primary spermatocytes have rounded nuclei with chromatin reticular network (green arrows), round spermatids with pale rounded nuclei, prominent nucleoli (blue arrow) and elongated spermatids with elongated dark nuclei (thin red arrow arrow).Few spermatogonia with deeply stained nuclei (thick red arrow) and few intercellular spaces (S) are also seen. Sertoli cells show oval pale nuclei and prominent nucleoli (green zigzag arrow) near the basement membrane (green arrow head).Notice myoid cells (black zigzag arrow) and interstitial cells of Leydig (black arrow heads) with vesicular nucleus.(H\&E X1000).

PAS reaction: PAS stained cross sections of the testis of group I and II showed mild magenta red PAS (+ve) material in the interstitium, wall of blood vessels and moderate PAS +ve reaction in the thin regular basal lamina surrounding the seminiferous tubules, the spermatogenic cell, the surrounding membrane of spermatozoa in the lumen and the acrosomes of both round and elongated spermatids (fig.3a\&3b).PAS stained cross sections of the testis of group III (cyclophosamide treated group) showed intense positive reaction in the thickened irregular basement membrane, the interstitium and in the thickened wall of blood vessel.Overall reduction in the PAS reaction in the germinal epithelium except in surrounding membranes of spermatids (fig.3c). PAS stained cross sections of the testis of group IV (cyclophosphamide and vitamin $\mathrm{E}$ co-administered group) showed moderate PAS +ve in a well circumscribed basal lamina.Mild PAS +ve reaction in spermatogenic cells, acrosomes of elongated spermatids and spermatozoa.Moderate PAS +ve reaction in the interstium and in the wall of a blood vessel.Mild thickening of basement membrane (fig.3d).PAS stained cross sections of the testis of group $\mathbf{V}$ (cyclophosphamide withdrawal rats) were similar to group III (cyclophosphamide treated rats) (fig.3e). 


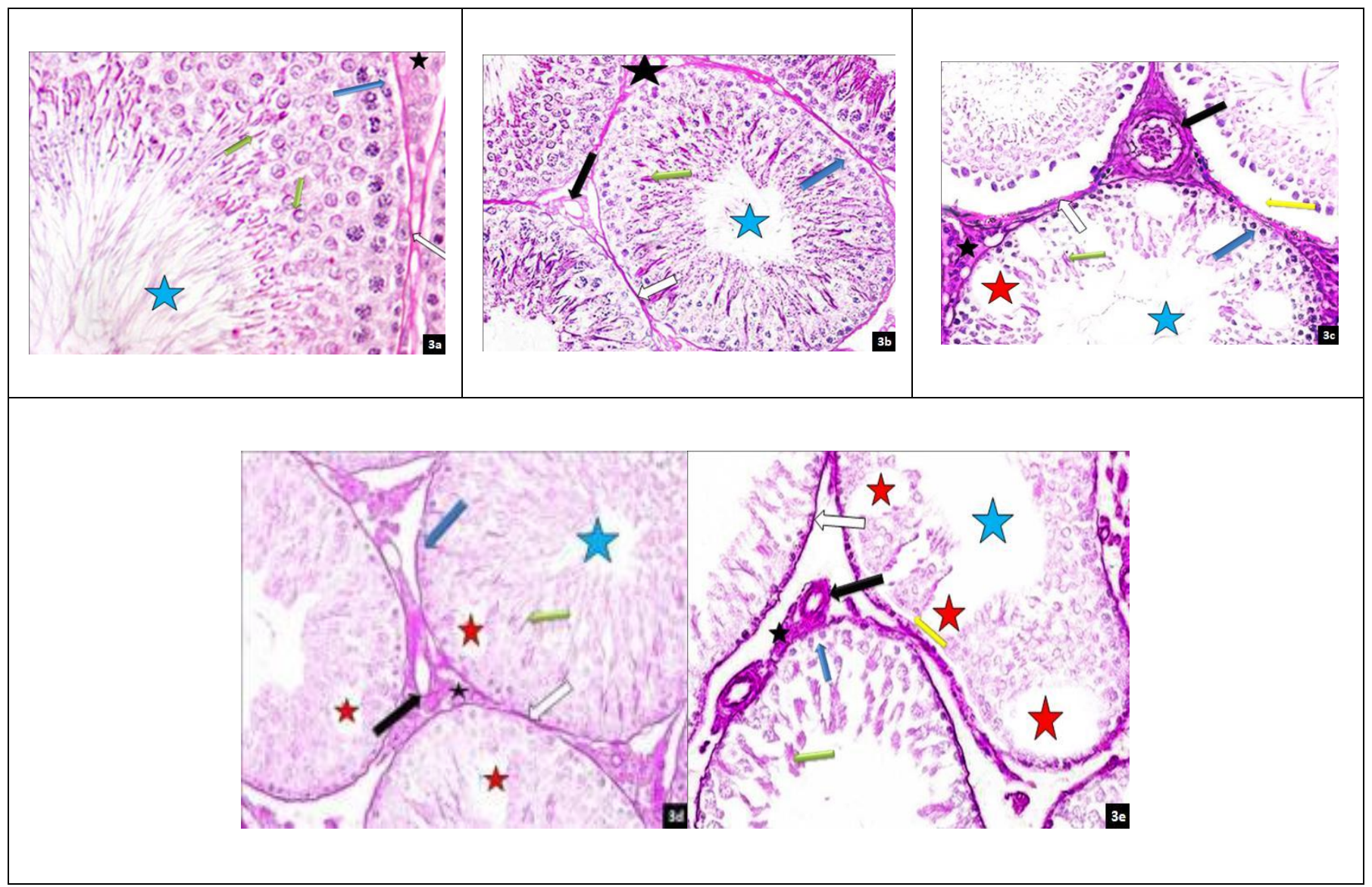

Fig.3. Photomicrographs of PAS stained sections of testis of control group (a) and vitamin E treated group (b) showing moderate PAS +ve reaction in the thin regular basal lamina (white arrows) surrounding the seminiferous tubules, the spermatogenic cells (blue arrow), the spermatozoa in the lumen (blue star) and the acrosomes of both round and elongated spermatids (green arrows). Notice mild PAS +ve reaction in the interstitium (black star) and in the wall of blood vessel (black arrow).Cp treated group (c) and $\mathrm{Cp}$ withdrwal group (e) showing intense positive reaction in the basement membrane (white arrow) which is thickened, the interstitium (black star) and in the thickened wall of blood vessel.Notice overall reduction in the PAS reaction in the germinal epithelium (blue arrow) except in surrounding membranes of spermatids (green arrow).Notice thinning of germinal epithelium with wide intercellular vacuoles (red star), separation of epithelium (yellow arrow) from the basement membrane and few sperms in the lumen (blue star).Cp and vitamin E treated group (d) showing moderate PAS +ve in a well circumscribed basal lamina (white arrows).Mild PAS + ve reaction in spermatogenic cells (blue arrow), acrosomes of elongated spermatids (green arrows) and spermatozoa (blue star) in the lumen. Notice the moderate PAS +ve reaction in the interstium (black star) and in the wall of a blood vessel (black arrow).Few intercellular vacuoles (red star) are also noticed in the germinal epithelium. (PAS X400). 


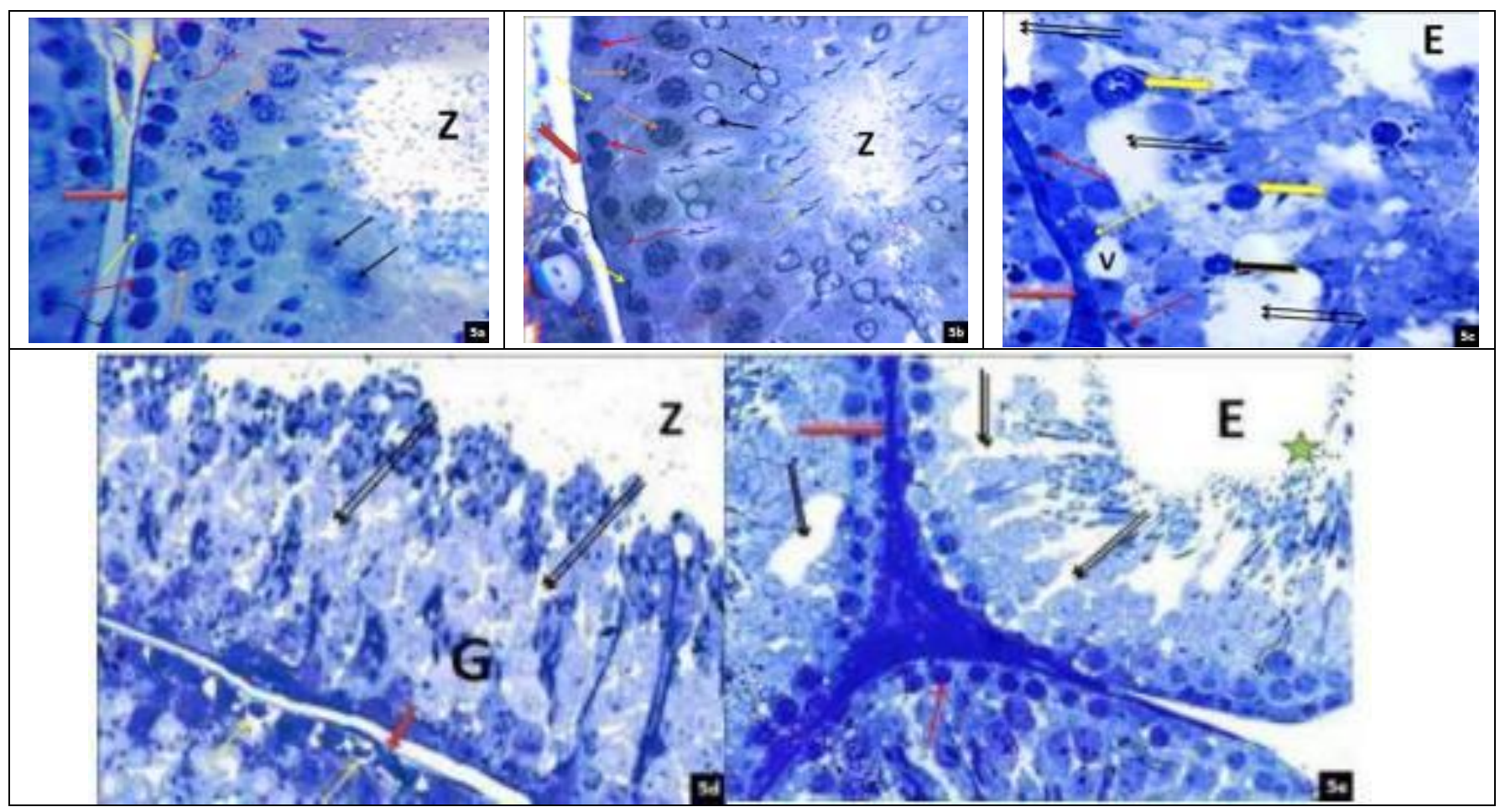

Fig.4. Photomicrographs of toluidine blue stained sections of testes of the control group (a) and vitamin $\mathrm{E}$ treated group (b) showing somniferous tubule that is surrounded by single layer of myoid cells (arrow) with flattened nuclei. It is lined by Sertoli cell with large pale triangular nucleus and prominent nucleolus (yellow arrow) and spermatogenic cells, dark spermatogonia type A (red arrow) resting on the basement membrane (red tailed arrow), pale spermatogonia type A (red zigzag arrow), primary spermatocytes showing meiotic figures (orange arrow), immature rounded spermatids with pale spherical nucleus and prominent nucleoli (black arrow), late elongated spermatid with dark elongated nucleus (yellow zigzag arrow) and spermatozoa $(Z)$ in the lumen.

Notice: the interstitial Leydig cell (orange zigzag arrow) in the interstitium. Cp treated group (c) and Cp withdrwal group (e) showing very few spermatogenic cells. Most of them are detatched from the basement membrane (red tailed arrow).

Spermatogenic cells with small pyknotic nuclei (red arrow).

Giant cells (yellow tailed arrows) in division are present between the lining germinal epithelium. Some primary spermatocytes (black tailed arrows) have condensed nuclei. Sertoli cells with vacuolated cytoplasm (yellow arrow) resting on the thickened wrinkled basement membrane (red tailed arrow).

Intercellular vacuoles (double arrows), loss of spermatozoa in the empty lumen (E) are also noticed. Some germ cells are exfoliated in the lumen of seminiferous tubule (star) and vacuolated(double zigzag arrows) germ cells are noticed in fig.e. $\mathrm{Cp}$ and vitamin $\mathrm{E}$ treated group (d) showing part of the seminiferous tubule that is lined with stratified germinal epithelium (G). Few Sertoli cells with cytoplasmic vacuoles (yellow arrow) are resting on the basement membrane (red tailed arrow).Few intercellular vacuoules (double arrows) can be detected between spermatogenic cells. Numerous spermatozoa $(\mathrm{Z})$ are noticed in the lumen.(Toluidine blue $\mathbf{X 1 0 0 0 )}$.

Immunohistochemical study: immunohistochemical stained sections of group I and II revealed strong immune reactivity of bcl-2 protein in the spermatids, moderate immune reactivity in primary spermatocytes, However, spermatogonia showed minimal immune reactivity of BCL2 (figs.5a\&5b).

Group III (cyclophosamide treated group) revealed negative immune reactivity in spermatogonia with minimal immune reactivity in spermatids and primary spermatocytes (fig.5c).

Group IV (cyclophosphamide concomitantly with vitamin $E$ treated rats) revealed moderate expression of bcl-2 protein in the spermatids and primary spermatocytes. Spermatogonia showed minimal expression of this antiapoptotic protein indicating that the apoptosis was higher in spermatogonia than in spermatids and spermatocytes (fig.5d).

Group V (cyclophosphamide withdrawal rats) were similar to group III (cyclophosphamide treated rats )(fig.5e). 


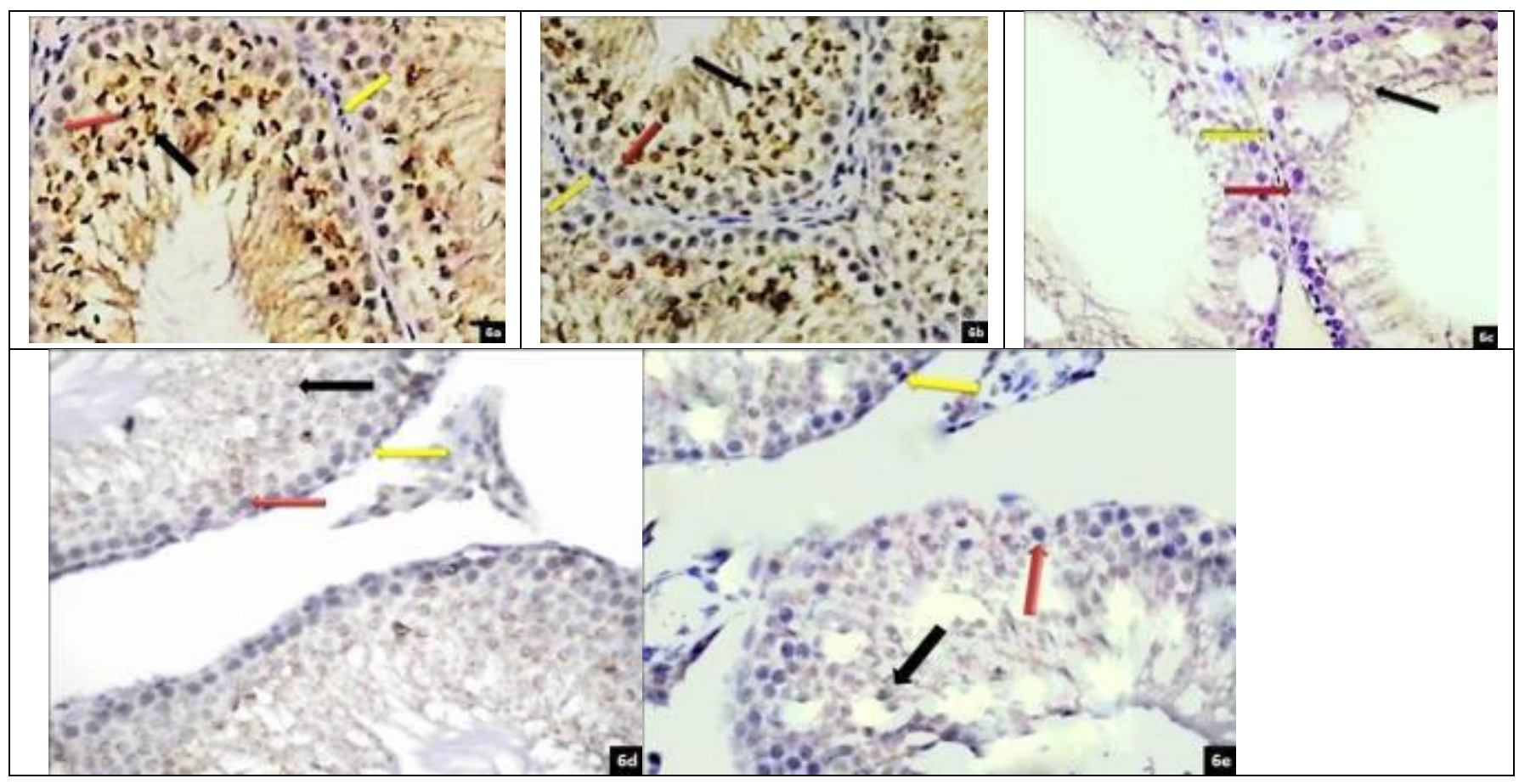

Fig.5. Photomicrographs of immunohistochemical stained sections of testes of the control group (a) and vitamin $\mathrm{E}$ treated group (b) showing strong immune reactivity of BCL2 in spermatids (black arrow) and moderate immune reactivity in primary spermatocytes (red arrows).Minimal immune reactivity is detected in spermatogonia (yellow arrow).Cp treated group (c) and $\mathrm{Cp}$ withdrwal group (e) showing minimal immune reactivity of BCL2 in spermatids (black arrow) and primary spermatocytes (red arrows) with negative immune reaction in spermatogonia (yellow arrow).Vitamin E treated group (d) showing moderate immune reactivity of bcl-2 in spermatids (black arrow) and primary spermatocytes (red arrow).Minimal immune reactivity in spermatogonia (yellow arrow). (Immunoperoxidase technique for bcl-2 X400)

Ultrastructural study: electron microscopic examination of ultrathinsections of group I and II groups (figs.6a\&6b) revealed that the seminiferous tubules were surrounded by flattened myoid cells and lined by stratified germinal epithelium arranged in several layers containing different types of spermatogenic cells and Sertoli cell. Pale type A spermatogonia with small euochromatic nucleus, primary spermatocytes with large rounded nucleus contained small irregular clumps of heterochromatin and rounded spermatids with rounded euchromatic nuclei. Their cytoplasm contained peripherally located mitochondria. The middle piece of the sperm contained centrally located microtubules which formed the axoneme of the flagella in the form of nine doublets of microtubules with 2 central singlets. The axoneme was surrounded by coarse longitudinal fibers. Mitochondria aggregated and surrounded the coarse fibers to form the mitochondrial sheath. In the principal piece, mitochondrial sheath was replaced by a fibrous sheath surrounded the outer dense fibers. The fibrous sheath was formed of two longitudinal columns and transverse ribs. Sertoli cells were situated near the basement membrane and exhibited euchromatic nuclei with characteristic groove (fig.6a).The cytoplasm contained dilated SER and lipid droplets. Part of Sertoli junction is noticed in the experimental group II (vitamin $\mathrm{E}$ treated group) (fig.6b). In the interstitial tissue, Leydig cells revealed oval euchromatic nuclei with peripheral thin rim of heterochromatin. The cytoplasm was rich in SER, mitochondria which appeared rounded or oval and large number of electron dense bodies.

In group III (cyclophosamide treated group) the basement membrane showed marked thickening and irregularity (fig.6c2).

The degenerated tubules were lined mainly by Sertoli cells with occasional germ cell. Sertoli cells showed numerous folds of the nuclear membrane with prominent nucleoli. Their cytoplasm had multiple variable sized vacuoles, small vacuolated mitochondria, smooth endoplasmic reticulum and electron dense granules (fig.6c1). Spermatogonia showed apoptotic changes as shrunken nucleus with irregular nuclear envelope Their cytoplasm contained vacuolated mitochondria, electron dense bodies and intracellular vacuoles (fig.6c2).Primary spermatocyte showed apoptotic features as: shrunken and condensed nucleus. The cytoplasm showed multiple vacuoles and vacuolated mitochondria (fig.6c2).Large intercellular 
spaces between the cell were numerous (figs.6c1\&c2).Cross section of the middle and principle pieces of sperms showed disturbed axoneme. The axoneme of the middle piece was surrounded by distorted and swollen mitochondrial sheath.Interstitial cell of Leydig showed shrunken nucleus with more condensed peripheral heterochromatin and widened perinuclear space. The cytoplasm showed numerous vacuoles, mitochondria, dilated smooth endoplasmic reticulum and variable sized electron dense bodies.

Group IV (cyclophosphamide concomitantly with vitamin $E$ treated rats) (fig.6d) revealed that some apparently normal seminiferous tubules that were ensheathed by a relatively normal basement membrane and lined by Sertoli cells and spermatogenic cells including spermatogonia, primary spermatocytes and round spermatids. Sertoli cell exhibited oval euchromatic nucleus with prominent nucleolus, spermatogonia showed shrunk heterochromatic nucleus with irregular nuclear envelope, their cytoplasm showed few intracellular vacuoles, primary spermatocytes with large rounded nucleus contained small irregular clumps of heterochromatin, round spermatids with round euchromatic nuclei, their cytoplasm contained peripherally located mitochondria, more developed spermatid showed flattened Golgi saccules in close relation to acrosome. Intercellular vacuoles weare few. Cross sections in the sperms showed the mid, principle and end pieces. In the mid pieces the axoneme was surrounded by fibrous and abnormal mitochondrial sheaths The mitochondria in their sheath showed mild swelling, vacuolization and distortion. Leydig cells had large oval euchromatic nuclei with widened perinuclear space, their cytoplasm contained numerous mitochondria and dilated sER large intercellular spaces between the cells.

Group V (cyclophosphamide withdrawal rats) were similar to group III (cyclophosphamide treated rats) and revealed Sertoli cells with shrunken nucleus, its cytoplasm contained abnormally vacuolated mitochondria, electron dense granules and SER (fig.6e1).

Spermatids with shrunken nuclei were observed, while others contained euchromaic nuclei and acrosomal caps (fig.6e2).

Some spermatids were detected with abnormally distributed mitochondria (fig.6e1).Thick basement membrane and prominent intercellular separations were detected (figs.6e1\&e2).

Disturbed axoneme of the different pieces (PP\&EP) of sperms were detected and the end pieces showed multiple vacuoles of variable sizes. Leydig cells showed shrunken nucleus and multiple vacuoles in their cytoplasm. 


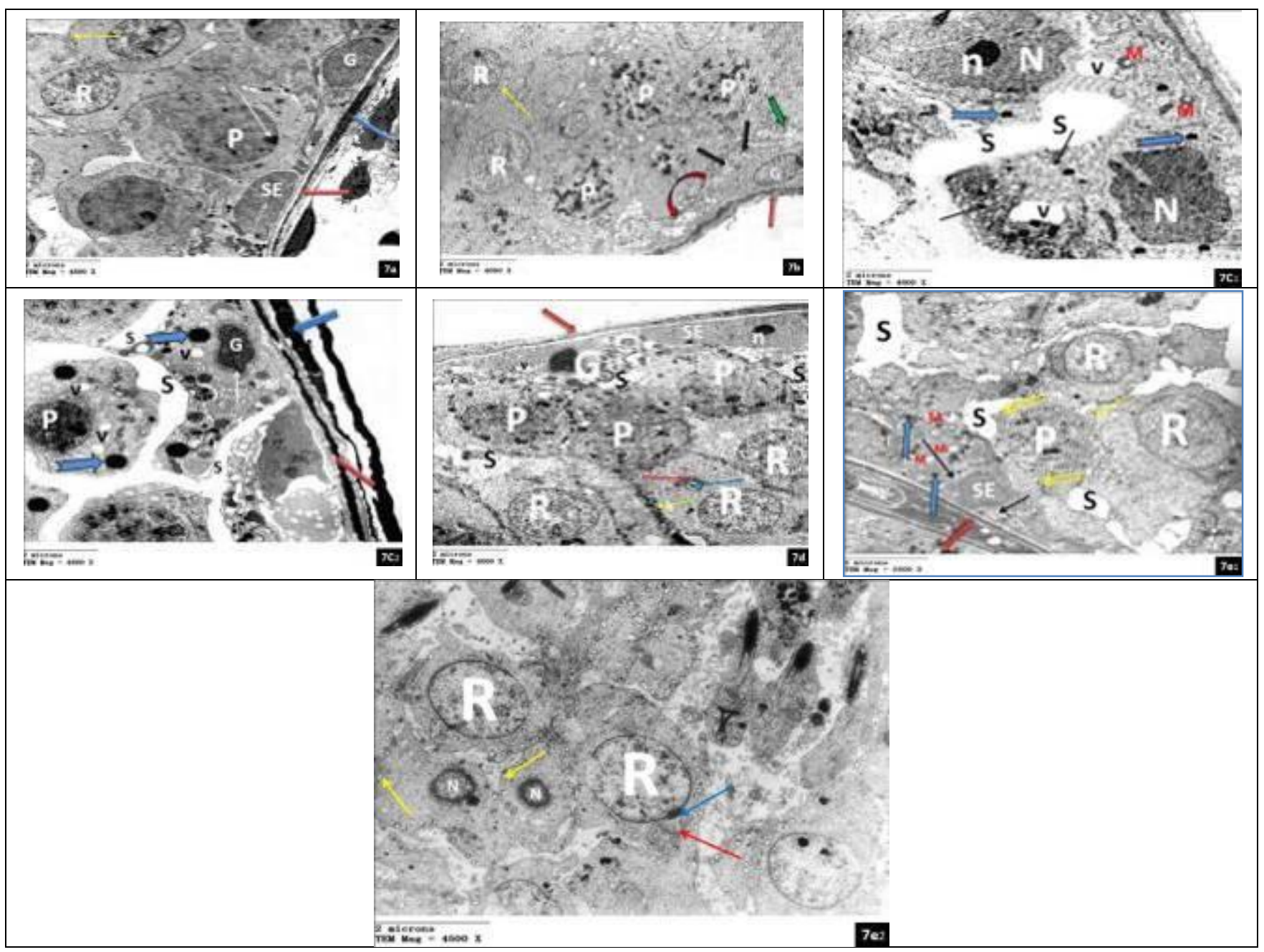

Fig.6. Electron micrographs of ultrathin sections in Albino rat's testes in the different studied groups. Control group (7a) and vitamin E treated group (7b) revealed that the seminiferous tubules were surrounded by thin regular basement membrane (red arrow), flattened myoid cells (blue arrow) and lined by stratified germinal epithelium arranged in several layers containing different types of spermatogenic cells and Sertoli cell. Pale type A spermatogonia with small euochromatic nucleus $(\mathrm{G})$, primary spermatocytes with large rounded nucleus (P) containing small irregular clumps of heterochromatin (white arrow) and round spermatids (R) with round euchromatic nuclei.Their cytoplasm contains peripherally located mitochondria (yellow arrow).Sertoli cells were situated near the basement membrane and exhibited indented euchromatic nuclei (SE).

Their cytoplasm contained SER (black arrows) and lipid droplet (green tailed arrow). Part of Sertoli junction (curved red arrows) is noticed in the experimental group II (vitamin E treated group).In Cp treated group (c1\&c2) the basement membrane (red arrow) showed marked thickening and irregularity. The degenerated tubules were lined mainly by Sertoli cells with occasional germ cell in (fig.c1.) Sertoli cells indented nuclei $(\mathrm{N})$ with prominent nucleoli $(\mathrm{n})$. Their cytoplasm had multiple variable sized vacuoles (V), small vacuolated mitochondria (M), smooth endoplasmic reticulum (black arrows) and electron dense granules (blue tailed arrows).

In (fig.c2) Spermatogonia showed apoptotic changes as shrunken nucleus $(\mathrm{G})$ with irregular nuclear envelope (thin white arrow). Their cytoplasm containing vacuolated mitochondria $(\mathrm{M})$, electrone dense bodies (blue tailed arrows) and intracellular vacuoles $(\mathrm{V})$.

Primary spermatocyte showed apoptotic features as: shrunked condensed nucleus(P).

The cytoplasm showed multiple vacuoles (V) and vacuolated mitochondria (M).

Large intercellular spaces between the cells are numrrous (S).Vtamin E treated group (d) showing seminiferous tubules were ensheathed by a relatively normal basement membrane (thick red arrow) and lined by Sertoli cells and spermatogenic cells including spermatogonia, primary spermatocytes and round spermatids. Sertoli cell exhibits oval euchromatic nucleus (SE) with prominent nucleolus (n). Spermatogonia show shrunked heterochromatic nucleus (G) with irregular nuclear envelope, their cytoplasm show few intracellular vacuoles (v).primary spermatocytes with large rounded nucleus (P) 
containing small irregular clumps of heterochromatin (white arrow).Round spermatids with round euchromatic nuclei (R) are observed. Their cytoplasm contains peripherally located mitochondria (yellow arrow).

More developed spermatid shows flattened Golgi saccules (thin red arrow) in close relation to acrosomal granules (blue arrow).Notice intercellular vacuoles $(\mathrm{S})$ are few. Cp withdrwal group (e1) showing Sertoli cells shrunken nucleus (SE), its cytoplasm contains abnormally vacuolated mitochondria (M), electron dense granules (blue tailed arrows) and sER (black arrows).Spermatids (d) are also seen with abnormally distributed mitochondria (yellow arrow).

Also the thick basement membrane (red arrow) and prominent intercellular separation $(\mathrm{S})$ are observed. Fig.(e2) showing Spermatids with shrunken nuclei (N) among others with euchromaic nuclei (R) and acrosomal caps (blue arrow) in close relation with flattened saccules of Golgi (red arrows).

\section{MORPHOMETRICAL and STATISTICAL RESULTS}

Statistical analysis of the morphometrical results in random fields using one way ANOVA (analysis of variance) test (for parametric results) showed a highly statistically significant difference between the different groups as the $\mathrm{P}$ value $<0.001$ (the $\mathrm{P}$ value $<0.001$ was highly significant). By post hoc Tukey test for comparison between groups, for comparison in between groups, it was found that:

(1) Diagonal diameters: there was a highly significant decrease in the diagonal diameters of the seminiferous tubules $(\mathbf{P}<\mathbf{0 . 0 0 1})$ in $\mathrm{CP}$ only treated (group 3) and $\mathrm{CP}$ withdrawal (group 5) in relation to both the control (group 1) and vitamin E only (group 2). Also, there was a highly significant decrease in the diagonal diameters of seminiferous tubules only $(\mathbf{P}<\mathbf{0 . 0 0 1})$ in CP treated (group 3) and $\mathrm{CP}$ withdrawal (group 5) in relation to $\mathrm{CP}+$ vitamin $\mathrm{E}$ (group 4).However, there was a non statistically significant difference $(\mathbf{p}>\mathbf{0 . 0 5})$ in $\mathrm{CP}$ + vitamin E (group 4) and vitamin E only (group 2) in comparison to control (group 1).Also, there was a non statistically significant difference $(\mathbf{p}>\mathbf{0 . 0 5})$ in $\mathrm{CP}+$ vitamin $\mathrm{E}$ (group 4) in comparison to vitamin $\mathrm{E}$ only (group 2) and $\mathrm{CP}$ withdrawal (group 5 ) in relation to $\mathrm{CP}$ only treated (group 3 ).(Table 1).

(2) Epithelium height: there was a highly significant decrease in the epithelium height $(\mathbf{P}<\mathbf{0 . 0 0 1})$ in $\mathrm{CP}$ only treated (group 3) and CP withdrawal (group 5) in relation to both control (group 1) and vitamin $\mathrm{E}$ only (group 2).Also, there was a highly significant decrease in the epithelium height $(\mathbf{P}<\mathbf{0 . 0 0 1})$ in $\mathrm{CP}$ only treated (group 3) and CP withdrawal (group 5) in relation to $\mathrm{CP}+$ vitamin $\mathrm{E}$ (group 4).However, there was a non statistically significant difference $(\mathbf{p}>\mathbf{0 . 0 5})$ in $\mathrm{CP}+$ vitamin E (group 4) and vitamin E only (group 2) in comparison with the control (group 1).Also, there was a non statistically significant difference $(\mathbf{p}>\mathbf{0 . 0 5})$ in $\mathrm{CP}+$ vitamin $\mathrm{E}$ (group 4) in comparison to vitamin E only (group 2) and $\mathrm{CP}$ withdrawal (group 5) in relation to $\mathrm{CP}$ only treated (group 3).(Table 2).

(3) Area \% of collagen fibers : there was a highly significant increase in area \% of collagen fibers $(\mathbf{P}<\mathbf{0 . 0 0 1})$ in CP only treated (group 3) and CP withdrawal (group 5) in relation to both control (group 1) and vitamin E only (group 2). Also, there was a significant increase in area \% of collagen fibers $(\mathbf{p}<\mathbf{0 . 0 1})$ in $\mathrm{CP}+$ vitamin $\mathrm{E}$ (group 4) in relation to groups $(1 \& 2)$ and a significant decrease in relation to groups ( $3 \& 5)$. However, there was a non statistically significant difference $(\mathbf{p}>\mathbf{0 . 0 5})$ in $\mathrm{CP}$ withdrawal (group 5) in relation to $\mathrm{CP}$ only treated (group 3) and vitamin E only (group 2) in relation to control (group 1).(Table 3).

(4) Area \% of bcl-2 expression in the germinal epithelium: there was a highly significant decrease in area\% of bcl-2 expression in the germinal epithelium of seminiferous tubules $(\mathbf{P}<\mathbf{0 . 0 0 1})$ in CP only treated (group 3) and CP withdrawal (group 5) in relation to both control (group 1) and vitamin E only (group 2). Also, there was a significant decrease in bcl-2 expression in the germinal ( $\mathbf{p}<\mathbf{0 . 0 1})$ in $\mathrm{CP}+$ vitamin E (group 4) in relation to groups $(1 \& 2)$ and a significant increase in relation to groups ( $3 \& 5)$. However, there was a non statistically significant difference $(\mathbf{p}>\mathbf{0 . 0 5})$ in $\mathrm{CP}$ withdrawal (group 5) in relation to $\mathrm{CP}$ only treated (group 3) and vitamin E only (group 2) in relation to control (group1).(Table 4).

(5) The optical density of bcl-2 expression in the germinal epithelium: there was a highly significant decrease $(\mathbf{P}<\mathbf{0 . 0 0 1})$ in $\mathrm{CP}$ only treated (group 3) and CP withdrawal (group 5) in relation to both control (group 1) and vitamin E only (group 2). Also, there was a significant decrease $(\mathbf{p}<$ 0.01)in CP + vitamin E (group 4) in relation to groups $(1 \& 2)$ and a significant increase in relation to groups ( $3 \& 5)$. However, there was a non statistically significant difference $(\mathbf{p}>\mathbf{0 . 0 5})$ in vitamin E only (group 2) in relation to control (group1).(Table 5). 
Table 1: comparison between the diagonal diameters findings among the studied groups

\begin{tabular}{|c|c|c|c|}
\hline \multirow{2}{*}{$\begin{array}{l}\text { Animal groups } \\
\text { (n=10 each group) }\end{array}$} & \multicolumn{2}{|c|}{ Diagonal diameters $(\mu \mathrm{m})$} & \multirow{2}{*}{$\begin{array}{l}\mathbf{P} \\
\text { value\# }\end{array}$} \\
\hline & Mean \pm SD & Range & \\
\hline Group 1: Control (saline) group & $310.2 \pm 62.4$ & $243.7-650.8$ & \\
\hline Group 2: Vitamin E only & $304.2 \pm 59.2$ & $223.6-466.1$ & $P 1=0.31 \mathrm{NS}$ \\
\hline $\begin{array}{l}\text { Group 3: } \\
\text { Cyclophosphamide only }\end{array}$ & $261.1 \pm 42.9$ & $175.7-328.1$ & $\begin{array}{l}\mathrm{P} 1 * * \\
\mathrm{P} 2 * *\end{array}$ \\
\hline $\begin{array}{l}\text { Group 4: } \\
\text { Cyclophosphamide + Vitamin E }\end{array}$ & $299.4 \pm 63.2$ & $202.01-412.1$ & $\begin{array}{l}\mathrm{P} 1=\mathbf{0 . 2 7} \mathbf{N S} \\
\mathrm{P} 2=\mathbf{0 . 3 1} \mathbf{N S} \\
\mathrm{P} 3 * *\end{array}$ \\
\hline $\begin{array}{l}\text { Group 5: } \\
\text { Cyclophosphamide withdrawal } \\
\text { group }\end{array}$ & $264.8 \pm 46.4$ & $182.5-352.1$ & $\begin{array}{l}\mathrm{P} 1 * * \\
\mathrm{P} 2 * * \\
\mathrm{P} 3=\mathbf{0 . 3 4} \mathbf{N S} \\
\mathrm{P} 4 * *\end{array}$ \\
\hline
\end{tabular}

F test $=8.6 P$ value $=<0.001$

SD: standard deviation, P: probability, *: Significant $(\mathrm{p}<0.01),{ }^{* *}$ : Highly Significant $(\mathrm{p}<0.001)$, NS: non- significant (p> 0.05), \#: post hoc Tukey, P1: significance in relation to group 1, P2: significance in relation to group 2, P3: significance in relation to group 3, P4: significance in relation to group 4.

Table 2: comparison between the epithelial heights among the studied groups

\begin{tabular}{|c|c|c|c|}
\hline \multirow{2}{*}{$\begin{array}{l}\text { Animal groups } \\
(n=10 \text { each group) }\end{array}$} & \multicolumn{2}{|c|}{ Epithelial height $(\mu \mathrm{m})$} & \multirow{2}{*}{$P$ value\# } \\
\hline & Mean \pm SD & Range & \\
\hline Group 1: Control (saline) group & $74.8 \pm 16.2$ & $45.65-109$ & \\
\hline Group 2: Vitamin E only & $71.72 \pm 13.2$ & $57.24-91.24$ & $P 1=0.64$ NS \\
\hline Group 3: Cyclophosphamide only & $43.14 \pm 11.2$ & $31.12-71.65$ & $\begin{array}{l}\mathrm{P} 1 * * \\
\mathrm{P} 2 * *\end{array}$ \\
\hline $\begin{array}{l}\text { Group 4: } \\
\text { Cyclophosphamide + } \\
\text { Vitamin E } \\
\end{array}$ & $69.23 \pm 9.84$ & $49.34-82.14$ & $\begin{array}{l}\mathrm{P} 1=0.34 \mathrm{NS} \\
\mathrm{P} 2=0.64 \mathrm{NS} \\
\mathrm{P} 3 * *\end{array}$ \\
\hline $\begin{array}{l}\text { Group 5: } \\
\text { Cyclophosphamide withdrawal group }\end{array}$ & $46.24 \pm 9.15$ & $32.52-67.25$ & $\begin{array}{l}\mathrm{P} 1 * * \\
\mathrm{P} 2 * * \\
\mathrm{P} 3=0.42 \mathrm{NS} \\
\mathrm{P} 4 * *\end{array}$ \\
\hline
\end{tabular}

F test $=6.9 P$ value $=<0.001$, SD: standard deviation, P: probability, $*$ : Significant $(\mathrm{p}<0.01),{ }^{*} *$ : Highly Significant $(\mathrm{p}<0.001)$, NS: non- significant ( $\mathrm{p}>0.05)$, \#: post hoc Tukey, P1: significance in relation to group 1, P2: significance in relation to group 2, P3: significance in relation to group 3, P4: significance in relation to group 4

Table 3: comparison between the area percent of collagen fibers among the studied groups

\begin{tabular}{|c|c|c|c|}
\hline \multirow{2}{*}{$\begin{array}{l}\text { Animal groups }(\mathrm{n}=10 \text { each } \\
\text { group) }\end{array}$} & \multicolumn{2}{|c|}{ Tubular area $\left(\mu \mathrm{m}^{2}\right)$} & \multirow{2}{*}{$\begin{array}{l}\mathbf{P} \\
\text { value\# }\end{array}$} \\
\hline & Mean \pm SD & Range & \\
\hline Group 1: Control (saline) group & $10.37 \pm 1.5$ & $8.3-16.1$ & \\
\hline $\begin{array}{l}\text { Group 2: } \\
\text { Vitamin E only }\end{array}$ & $12.1 \pm 3.5$ & $8.6-22.8$ & $\mathbf{P 1}=0.77 \mathrm{NS}$ \\
\hline $\begin{array}{l}\text { Group 3: } \\
\text { Cyclophosphamide only }\end{array}$ & $22.8 \pm 3.6$ & $17.2-27.5$ & $\begin{array}{l}\mathrm{P} 1 * * \\
\mathrm{P} 2 * *\end{array}$ \\
\hline $\begin{array}{l}\text { Group 4: } \\
\text { Cyclophosphamide + Vitamin E }\end{array}$ & $15.5 \pm 2.1$ & $9.3-21.2$ & $\begin{array}{l}\mathrm{P} 1 * \\
\mathrm{P} 2 * \\
\mathrm{P} 3 *\end{array}$ \\
\hline $\begin{array}{l}\text { Group 5: } \\
\text { Cyclophosphamide withdrawal group }\end{array}$ & $19.2 \pm 2.5$ & $15.2-24.1$ & $\begin{array}{l}\mathrm{P} 1 * * \\
\mathrm{P} 2 * * \\
\mathrm{P} 3=0.86 \mathrm{NS} \\
\mathrm{P} 4 *\end{array}$ \\
\hline
\end{tabular}

F test $=$ 9.3P value $=<\mathbf{0 . 0 0 1}$, SD: standard deviation, P: probability, ${ }^{*}$ : Significant $(\mathrm{p}<0.01), * *$ : Highly Significant ( $p<0.001$ ), NS: non- significant ( $>$ > 0.05), \#: post hoc Tukey,P1: significance in relation to group 1, P2: significance in relation to group 2, P3: significance in relation to group 3, P4: significance in relation to group 4

Table 4: comparison between the area percent of bcl-2 expression among the studied groups 
ejhm.journals.ekb.eg

\begin{tabular}{|c|c|c|c|}
\hline \multirow{2}{*}{$\begin{array}{l}\text { Animal groups } \\
(n=10 \text { each group) }\end{array}$} & \multicolumn{2}{|c|}{ Area \% of bcl-2 expression } & \multirow{2}{*}{$\begin{array}{l}\mathbf{P} \\
\text { value\# }\end{array}$} \\
\hline & Mean \pm SD & Range & \\
\hline $\begin{array}{l}\text { Group } 1 \\
\text { Control (saline) group }\end{array}$ & $5.98 \pm 1.41$ & $2.56-8.19$ & \\
\hline $\begin{array}{l}\text { Group } 2 \\
\text { Vitamin E only }\end{array}$ & $5.12 \pm 1.13$ & $2.35-7.45$ & $P 1=0.79$ NS \\
\hline $\begin{array}{l}\text { Group } 3 \\
\text { Cyclophosphamide only }\end{array}$ & $2.84 \pm 1.3$ & $1.01-3.36$ & $\begin{array}{l}\mathrm{P} 1 * * \\
\mathrm{P} 2^{* *}\end{array}$ \\
\hline $\begin{array}{l}\text { Group } 4 \\
\text { Cyclophosphamide + Vitamin E }\end{array}$ & $3.98 \pm 1.9$ & $3.25-7.65$ & $\begin{array}{l}\mathrm{P} 1 * \\
\mathrm{P} 2^{*} \\
\mathrm{P} 3 *\end{array}$ \\
\hline $\begin{array}{l}\text { Group } 5 \\
\text { Cyclophosphamide withdrawal group }\end{array}$ & $2.98 \pm 0.8$ & $1.59-4.01$ & $\begin{array}{l}\mathrm{P} 1 * * \\
\mathrm{P} 2 * * \\
\mathrm{P} 3=\mathbf{0 . 5 2} \text { NS } \\
\mathrm{P} 4 *\end{array}$ \\
\hline
\end{tabular}

\section{F test $=7.7 \quad P$ value $=<0.001$}

SD: standard deviation, P: probability, *: Significant $(\mathrm{p}<0.01)$, **: Highly Significant $(\mathrm{p}<0.001)$, NS: nonsignificant ( $>$ > 0.05), \#: post hoc Tukey, P1: significance in relation to group 1, P2: significance in relation to group 2, P3: significance in relation to group 3, P4: significance in relation to group 4

Table 5: comparison between the optical densities of bcl-2 among the studied groups

\begin{tabular}{|c|c|c|c|}
\hline \multirow{2}{*}{$\begin{array}{l}\text { Animal groups } \\
(\mathrm{n}=10 \text { each group })\end{array}$} & \multicolumn{2}{|c|}{$\begin{array}{l}\text { optical densities of bcl-2 } \\
\text { expression }\end{array}$} & \multirow{2}{*}{$\begin{array}{l}P \\
\text { value\# }\end{array}$} \\
\hline & Mean \pm SD & Range & \\
\hline $\begin{array}{l}\text { Group 1 } \\
\text { Control (saline) group }\end{array}$ & $0.95 \pm 0.04$ & $0.92-1.92$ & \\
\hline $\begin{array}{l}\text { Group } 2 \\
\text { Vitamin E only }\end{array}$ & $0.94 \pm 0.08$ & $0.91-1.85$ & $P 1=0.61 \mathrm{NS}$ \\
\hline $\begin{array}{l}\text { Group } 3 \\
\text { Cyclophosphamide only }\end{array}$ & $0.86 \pm 0.04$ & $0.81-0.93$ & $\begin{array}{l}\mathrm{P} 1 * * \\
\mathrm{P} 2 * *\end{array}$ \\
\hline $\begin{array}{l}\text { Group } 4 \\
\text { Cyclophosphamide + Vitamin E }\end{array}$ & $0.90 \pm 0.03$ & $0.85-1.1$ & $\begin{array}{l}\mathrm{P} 1 * \\
\mathrm{P} 2 * \\
\mathrm{P} 3 *\end{array}$ \\
\hline $\begin{array}{l}\text { Group } 5 \\
\text { Cyclophosphamide withdrawal group }\end{array}$ & $0.88 \pm 0.02$ & $0.86-0.93$ & $\begin{array}{l}\text { P1** } \\
\text { P2** } \\
\text { P3* } \\
\text { P4* }\end{array}$ \\
\hline
\end{tabular}

F test $=7.5 P$ value $=<0.001$

SD: standard deviation, P: probability, *: Significant ( $\mathrm{p}<0.01)$, **: Highly Significant $(\mathrm{p}<0.001)$, NS: nonsignificant ( $p>0.05$ ), \#: post hoc Tukey, P1: significance in relation to group 1, P2: significance in relation to group 2, P3: significance in relation to group 3, P4: significance in relation to group 4

\section{DISCUSSION}

In the current work, the histological, immunohistochemical and ultrasractural results of rats of group II administrated vitamin E were similar to the control group I. These results are in agreement with results of Hong et al. ${ }^{(13)}$ who mentioned that the thickness of the germinal epithelium showed no significant changes between the control and vitamin Etreated group. They also found that even the diameter of the seminiferous tubules was the same. So, the results of both groups will discussed together.

In the current work, hematoxylin and eosin stained sections of both groups (I\&II ) revealed that the testes of the adult male rats were surrounded by outer tunica albuginea and inner tunica vasculosa that contained blood vessels. The testicular parenchyma was composed of packed, well organized oval or round seminiferous tubules and separated by narrow interstitium that contained clusters of interstitial cells and blood vessels. These results are in agreement with those of Verma and Nai ${ }^{(14)}$. These tubules were surrounded by thin and regular abasement membrane formed of connective tissue fibers and myoid cells and lined by stratified germinal epithelium including many layers of spermatogenic cells and Sertoli cells. The same results were reported by Singh ${ }^{(15)}$. The spermatogenic cells included: spermatogonia, primary spermatocytes, spermatids and spermatozoa. Spermatogonia were of different types (dark type A 
and pale type A) resting on thin and regular basement membrane. These results are in concomitant with those described by Pawlina ${ }^{(16)}$ and Siu and Cheng ${ }^{(17)}$. They added that the BM is considered as a nutritional and functional support for both germ and somatic Sertoli cell. Spermatogonia were resting on the basement membrane and had different types ; dark type A spermatogonia with oval dark nuclei, pale type A spermatogonia with pale oval nuclei and primary spermatocytes which were the largest spermatogenic cells. They were rounded in shape and had central rounded vesicular nuclei containing characteristic reticular network of chromatin. These findings are consistent with results of Pawlina ${ }^{(16)}$.Two types of spermatids were detected: rounded immature spermatids and elongated mature spermatids. Rounded spermatids had pale round nuclei. Elongated spermatids showed elongated dark nuclei. Spermatozoa were visible near the lumen and their flagella were projecting into the lumen. These findings are also described by Singh ${ }^{(15)}$. Sertoli cells were present near the basement membrane and had oval or triangular pale nuclei and prominent nucleoli. The spaces between the seminiferous tubules were filled with connective tissue containing groups of Leydig cells, blood vessels and collagen fibers that were stained blue by Mallory's trichrome stain. Interstitial cells of Leydig were rounded or polygonal in shape with acidophilic cytoplasm and rounded or oval vesicular nuclei. Junqueira ${ }^{(18)}$ reported the same findings. In the current work, toluidine blue stained semithin sections of both groups (I\&II ) showed that seminiferous tubules were surrounded by thin basal laminae with single layer of flat myoid cells and were lined by Sertoli and spermatogenic cells in the form of: spermatogonia, primary spermatocytes, immature round spermatid, mature elongated spermatids and spermatozoa. These findings are consistent with ${ }^{(\mathbf{1 9 )}}$.In the current work, immunohistochemical examination of both groups (I\& II ) revealed strong immune reactivity of bcl-2 protein in spermatids and moderate immune reactivity in primary spermatocytes. However, spermatogonias showed minimal immune reactivity of bcl-2. Similar findings were reported by Hoda et al. (20) who reported that the germ cell apoptosis were more in spermatogonia and to less extent in spermatocytes. In addition, He et al. ${ }^{(21)}$ found that the expression of bcl-2 protein is localized to acrosomal region of spermatids. Antonsson and Martinou ${ }^{(22)}$ stated that the B- cell lymphoma 2 (Bcl2) family of proto-oncogenes (apoptosis inhibiting gene products) encodes specific proteins, which regulate apoptosis under different physiological and pathological conditions. In the current work, the histological, immunohistochemical and ultrasractular results of rats of group $\mathrm{V}$ (cyclophosphamide withdrawal rats) were similar to group III (cyclophosphamide treated rats) except in few differences. These results are in agreement with results Kanno et al. ${ }^{(23)}$ who stated that these changes may be due to the side effects of $\mathrm{CP}$ which persist even after drug withdrawal. So, the results of both groups will be discuss together. In the current work, interstitial cells of Leydig were numerous and showed pyknotic nuclei. The same results were documented by Slimen $\boldsymbol{e t}$ al. ${ }^{\text {(24) }}$ after exposure of rats to malathion induced oxidative stress because oxidative stress and lipid peroxidation caused damaging of the biological membranes of Leydig cells. These finding were also proved by Amin and Hamza ${ }^{(25)}$ and Karawya and El-Nahas ${ }^{(26)}$.The presence of numerous Leydig cells might occur as a compensatory mechanism of Leydig cells affection which occurred secondary to positive feedback on the pituitary gland. However, the number of Leydig cells was not necessarily correlated with the hormone production. Some investigators confirmed that in some cases of increased number of Leydig cells, the testosterone production occurred in few Leydig cells only ${ }^{(27)}$. In the current work, toluidine blue semithin stained sections from both groups (III\&V) showed seminiferous tubules with many vacuoles of variable sizes in between germinal epithelium and very few spermatogenic cells. Most of them were detached from basement membrane. Spermatogonial cells showed small pyknotic nuclei. Sertoli cells showed vacuolated cytoplasm resting on the thickened wrinkled basement membrane. Giant cells in division were present between the lining germinal epithelium .Some primary spermatocytes had condensed nuclei , loss of spermatozoa in the empty lumen. This finding is in agreement with results of Hild $\boldsymbol{e t}$ al. ${ }^{(28)}$. They explained these vacuoles by degeneration of abnormal germ cells. They added that these vacuoles were corresponded to dilatation of extracellular spaces resulting from the premature exfoliation of germ cells. These intraepithelial vacuoles resulted in atrophy of the seminiferous tubules that was dependent on the dose and the period of treatment by cyclophosphamide. These apoptotic events could be triggered by testosterone deprivation and an excessive ROS level could directly trigger massive germ cell apoptosis in the testes ${ }^{(29)}$. In the present work, immune reactivity of bcl-2 as an anti apoptotic factor in both groups $(I I I \& V)$ revealed negative immune reactivity in spermatogonia, minimal immune reactivity in spermatids and primary spermatocytes. The B- cell lymphoma 2 (Bcl-2) family of proto-oncogenes (apoptosis inhibiting gene products) encodes specific proteins, which regulate programmed cell death under different physiological and pathological conditions ${ }^{\mathbf{2 2} 2)}$. In the current study, cross sections of the middle and principle pieces of sperms showed disturbed axoneme. The axoneme of the middle piece was surrounded by abnormal distorted mitochondrial with vacuolation. 
The axoneme was surrounded by distorted and swollen mitochondrial sheath. The end pieces in group (V) showed multiple vacuoles of variable sizes. These findings are in agreement with results Sawyer and Brown ${ }^{(30)}$ who stated that $\mathrm{CP}$ causes morphological changes in the spermatozoa and increase in the number of abnormal forms. They attributed these changes to abnormal spermatogenesis. Kaneto and Kishi ${ }^{(31)}$ stated that DNA microarray analysis could be detected these changes and alteration of the gene expression. Selvakumar et al. (4) demonstrated that the spermatozoa were more susceptible to oxidative damage, as their cell membranes contained high amount of polyunsaturated fatty acids and their cytoplasm contained low concentrations of scavenging enzymes. Finally we can summarize the findings of both groups (III\&V) as follows: the vacuoles in cytoplasm of spermatogenic cells might be due to lipid peroxidation with consequent damage to the cell membrane and cell organelles caused by $\mathrm{CP}$ with subsequent increase in their permeability .These results are in agreement with those of Sakr et al. ${ }^{(32)}$. Some authors stated that the vacuoles within the cytoplasm considered distended and pinched-off segments of the endoplasmic reticulum. They also reported that the cellular swelling may occur as a result of failure of energy-dependent ion pumps in the plasma membrane leading to failure to maintain ionic and fluid homeostasis or vacuolar degeneration ${ }^{(33)}$. The same authors reported that the nuclear pyknosis is feature of apoptosis and characterized by nuclear shrinkage with increased basophilia as its DNA condenses into a solid shrunken mass. The dilatation of SER that was noticed in the cytoplasm of some Sertoli and Leydig cells may reflect the accumulation of water inside it as a result of lipid peroxidation of the SER membranes ${ }^{(34)}$. Results of group (V) are nearly similar to group (III). Kanno et al. ${ }^{(23)}$ attributed these changes to the side effects of $\mathrm{CP}$ which persist even after drug withdrawal. Aguilar-Mahecha et al. ${ }^{(35)}$ mentioned that $\mathrm{CP}$ is a powerful alkylating agent that alkylate a range of cellular macromolecules such as mRNA and proteins that mediate the apoptotic response in susceptible germ cells. Moreover, CP may damage the DNA of genes required for germ cell apoptosis. In contrast, Eman et al. ${ }^{(36)}$ suggested that the long term administration of cyclophosphamide even in low dose may reduce apoptosis in germ cells. Baker and Aitken ${ }^{(37)}$ reported the same results and stated that the ability to regain spermatogenesis after cytotoxic drugs therapy depending on the types of drug used and the period of treatment. In contrary, Haubitz ${ }^{(38)}$ stated that even lower doses of CP for a short period could reduce the gonadal activities permanently.In the current study, the light microscope examination of the testes of rats of group IV (cyclophosphamide concomitantly with vitamin $\mathrm{E}$ treated rats) showed a significant improvement in the histological structure of the testis. The histological architecture of seminiferous tubules was more or less similar to the control group I. In the current work, toluidine blue stained sections from the animal of group IV (cyclophosphamide concomitantly with vitamin E treated rats) showed that the seminiferous tubules were lined with stratified germinal epithelium. Few Sertoli cells with cytoplasmic vacuoles were resting on the basement membrane. Few intercellular separations were detected between the spermatogenic cells. Numerous spermatozoa were detected in the lumen. Tamura $\boldsymbol{e t}$ al. ${ }^{\text {(39) }}$ stated similar finding.In the current work, Immunohistochemical study of the same group (IV) revealed moderate expression of bcl-2 protein in the spermatids and the primary spermatocytes. Spermatogonia showed minimal expression of this anti apoptotic protein indicating that the apoptosis was higher in spermatogonia than in spermatids and spermatocytes. These findings are in agreement with results of Banudevi et al. ${ }^{(40)}$ who detected increased the anti apoptotic protein in spermatogonia under the effect of vitamin E. They added that vitamin E could improve sperm production because this process is initiated from self-renewing population of immature spermatogonia. On the other hand, Selvakumar et al. (4) mentioned that the oxidative stress occurred in the testes of cyclophosphamide treated rats caused the release of reactive oxygen species. These ROS induced very harmful effects upon spermatocytes followed by spermatogonia and spermatids. This difference in the susceptibility of cells to cyclophosphamide toxicity may be explained by the difference in the activities of antioxidant and related enzymes within these cells. They added that vitamin E could reverse the functional consequences of lipid peroxidation through suppression of its chain reaction and production of scavenger antioxidants enzymes.Das $\boldsymbol{e t}$ al. ${ }^{(12)}$ studied the effect of oxidative stress on the process testosterone hormone synthesis. They reported that this oxidative stress could interfere with the activities of steroidogenesis enzymes. So, the process of steroidogenesis was inhibited which in turn led to decreased testosterone level in serum. Statistical analysis of the morphometrical results of diagonal diameters of seminiferous tubules and their epithelial height of the different studied groups revealed that there was a highly significant decrease in $\mathrm{CP}$ only treated (group 3) and CP withdrawal (group 5) in relation to both control (group 1) and vitamin E only (group 2).Also, there was a highly significant decrease in CP only treated (group 3) and CP withdrawal (group 5) in relation to $\mathrm{CP}+$ vitamin $\mathrm{E}$ (group 4).However, there was a non statistically significant difference $(\mathrm{p}>$ 0.05) in CP + vitamin E (group 4) and vitamin E only (group 2) in comparison to control (group 1).Also, there was a non statistically significant difference $(\mathrm{p}>$ 
0.05)in $\mathrm{CP}+$ vitamin E (group 4) in comparison to vitamin E only (group 2) and CP withdrawal (group 5) in relation to CP only treated (group 3). Sahoo et al. (41) observed similar findings; they referred these results to protective effect of vitamin $\mathrm{E}$ against the testicular oxidative stress.

Statistical analysis of morphometrical results of area $\%$ of collagen fibers revealed that, there was a highly significant increase in CP only treated (group 3) and $\mathrm{CP}$ withdrawal (group 5) in relation to both control (group 1) and vitamin E only (group 2). Also, there was a significant increase $\mathrm{n} \mathrm{CP}+$ vitamin E (group 4) in relation to groups (1\&2) and a significant decrease in relation to groups ( $3 \& 5)$. However, there was a nonstatistically significant difference $(p>0.05)$ in CP withdrawal (group 5) in relation to $\mathrm{CP}$ only treated (group 3) and vitamin E only (group 2) in relation to control (group 1).Excess collagen in groups $(3 \& 5)$ might result from either over production of collagen fibers or decrease in the rate of collagen remodeling by fibroblasts ${ }^{(42)}$. This tendency towards fibrosis may be one of the possible explanations for the shrinkage of the seminiferous tubules.

Statistical analysis of the results of area \% occupied by apoptotic cells and the optical density of expression of bcl-2 protein revealed that, there was a highly significant decrease CP only treated (group 3) and $\mathrm{CP}$ withdrawal (group 5) in relation to both control (group 1) and vitamin E only (group 2). Also, there was a significant decrease in bcl-2 expression in $\mathrm{CP}+$ vitamin $\mathrm{E}$ (group 4) in relation to groups (1\&2) and a significant increase in relation to groups $(3 \& 5)$. However, there was a non statistically significant difference in both CP withdrawal (group 5) in relation to $\mathrm{CP}$ only treated (group 3) and vitamin E only (group 2 ) in relation to control (group1) as regarding to the area\% of bcl-2 expression, but there was a non statistically significant difference only in vitamin E only (group 2) in relation to control (group1) as regarding to the optical density of bcl-2 expression. This finding revealed that the expression of this antiapoptotic protein varied in the different groups. In the spermatids and spermatocytes, the expression of bcl-2 protein varied from the maximum in control, vitamin $\mathrm{E}$ only and $\mathrm{CP}+$ vitamin $\mathrm{E}$ groups to moderate in the other groups. Tripathi and Jena ${ }^{(43)}$ reported that they were the least cells to be affected by apoptosis and their apoptotic cells either phagocytosed by Sertoli cells or transmitted to next generations. However, the expression of this protein was minimum in spermatogonia as these cells were the most common cells affected by apoptosis. These findings coincide with Sabik and Abd El-Rahman ${ }^{(44)}$ who added that the cyclophosphamide induced apoptosis in dose dependent and stage specific manner in spermatogonia and spermatocytes.

In conclusion, the present work showed that cyclophosphamide treatment produced hazardous effects on the histological structure of the testis. These effects appeared as destruction in the germinal epithelium and sperms. These alterations may lead to infertility as they persisted after stoppage of treatment. Supplementation with vitamin E produced relative improvement in the testicular tissue and seriological parameter. The present results proved that vitamin $\mathrm{E}$ supplementation was recommended under clinical supervision during cyclophosphamide treatment to minimize its side effects.

\section{REFERENCES}

1. Barton T, Robaire B and Hales B (2005): Epigenetic programming in the perimplantation rat embryo is disrupted by chronic paternal cyclophosphamide exposure. PANS., 102(22):7865-7870.

2. Perini P, Calabrese M, Rinaldi L et al. (2007): The safety profile of cyclophosphamide in multiple sclerosis therapy. Expert. Drug Saf., 6:183-190.

3. Emadi A, Jones RJ and Brodsky RA (2009): Cyclophosphamide and cancer: golden anniversary. Nature Reviews. Clinical Oncology, 6 (11):63847-63856.

4. Selvakumar E, Prahalathan C, Sudharsan P et al. (2006): Protective effect of lipoic acid on cyclophosphamide induced testicular toxicity. Clin Chim Acta., 367(1-2):114-123.

5. Kim W, Kim SH, Park SK et al. (2012): Astragalus membranes ameliorates reproductive toxicity induced by cyclophosphamide in male mice. Phytother. Res., 26:14181421.

6. Ghosh D, Das U, Ghosh S et al. (2002): Testicular gametogenic and steroidogenic activities in cyclophosphamide treated rat: A correlative study with testicular oxidative stress. Drug and Chemical Toxicol., 25(3):281-292.

7. Turk G, Geribasi AO, Sakin F et al. (2010): Antiperoxidative and anti-apoptotic effects of lycopene and ellagic acid on cyclophosphamide-induced testicular lipid peroxidation and apoptosis. Fertil Dev., 22:587-96.

8. Laura $S$ (2004): Regulation of male germ cell apoptosis by sphingosine-1-phosphate. Academic dissertation. University of Helsinki, Finland., Pp: 1-76.

9. Shathish K, Reena D, Guruvayoorappan C (2012): Chemoprotective effect of Decalepishamiltonii against cyclophosphamide-induced toxicity. J Exp Ther Oncol., 9:291-301.

10. Vijayaraghavan R, Suribabu C, Sekar B et al. (2005): Protective role of vitamin $\mathrm{E}$ on the oxidative stress in Hansen's disease (leprosy) patients. European J of Clin Nut., 59:1121-1128.

11. Bartsch H, Nair J (2000): Ultrasensitive and specific detection methods for exocyclic DNA adducts: Markers for lipid peroxidation and oxidative stress. Toxicol., 153:105-114.

12.Das S, Maiti R, Ghosh D (2006): Management of fluoride induced testicular disorders by calcium and vitamin E co-administration in the albino rat. Reprod Toxicol., 22:606-612.

13.Hong Z, Hailing L, Hui M et al. (2009): Effect of vitamin $\mathrm{E}$ supplement in diet on antioxidant ability of testis in boer goat. Animal reprod Sci., 113:93-101.

14. Verma RJ, Nair A (2001): Ameliorative effect of vitamin $E$ on aflatoxin- induced lipid peroxidation in the 
testis of mice. Asian J Androl., 3:217- 21.

15.Singh I (2011): Male reproductive system. In textbook of human histology with colour atlas \&practical guide. 6th ed., Jaypee Brothers, Medical Publishers, New Delhi, India. Pp. 290- 303

16.Pawlina W (2017): Histology. A Text and Atlas with Correlated Cell and Molecular Biology, 7th ed. Lippincott Williams \& Wilkins, Baltimore and Philadelphia. Pp: 734-738.

17.Siu M, Cheng Y (2004): Dynamic cross talk between cell and extracellular matrix in testis. Bioass., 26(4):978992.

18. Junqueira L (2013): Basic Histology. Text and Atlas, 13th ed., Lang Medical Books, McGrow-Hill. Pp: 418420.

19.Fawcett DW, Jensh RP (2002): Male reproductive system. In Bloom \& Fawcett's Concise Histology, Arnold, London, Pp. 269-282.

20.Hoda HA, Nashwa SW, Maha AA et al. (2017): Histological and immunohistochemical study of cyclophosphamide effect on adult rat testis. International Journal of Scientific Reports, 3: 39-48.

21.He D, Li X, Yue $\mathrm{L}$ et al. (2008): Effect of cyclophosphamide on spermatogonial stem cells. Zhonghua Nan Ke Xue., 12(5):387-390.

22. Antonsson B, Martinou JC (2000): The Bcl-2 protein family. Exp Cell Res., 256: 50-57.

23. Kanno T, Sensiate L, Paula $N$ et al. (2009): Toxic effects of different doses of cyclophosphamide on the reproductive parameters of male mice. Barazilian J Pharmaceut Sci., 45(2): 313-319.

24.Slimen S, El Fazaa S, Gharbi N (2014): Oxidative stress and cytotoxic potential of anticholinesterase insecticide, malathion in reproductive toxicology of male adolescent mice after acute exposure. Iranian Journal of Basic Medical Sciences, 17(7): 522-5.

25.Amin A, Hamza AA (2005): Hepatoprotective effects of hibiscus, rosmarinus and salvia on azathioprineinduced toxicity in rats. Life Sci., 77(3): 266-278.

26. Karawya FS, El-Nahas AF (2006): The protective effect of vitamin $\mathrm{C}$ on azathioprine induced seminiferous tubular structural changes and cytogenetic toxicity in albino rats. Cancer Therapy, 4: 125-134.

27.Holstein A, Schulze W, Davidoff M (2003): Understanding spermatogenesis is a prerequisite for treatment. Reprod Biol and Endocrinol., 1:1-17.

28. Hild SA, Reel JR, Larner JM et al. (2001): Disruption of spermatogenesis and Sertoli cell structure and function by the indenopyridine CDB-4022 in rats. Biol Reprod., 65:1771-1779.

29. Wang RS, Yeh S, Tzeng CR et al. (2009): Androgen receptor roles in spermatogenesis and fertility: lessons from testicular cell-specific androgen receptor knockout mice. Endocr Rev., 30(2): 119-132.

30. Sawyer D, Brown D (2000): Diminished decondensation and DNA synthesis in activated sperm from rats treated with cyclophosphamide. Toxicol Letters, 114:19-26.

31. Kaneto M, Kishi K (2003): Spermatogenic dysfunction and its evaluation by computer-assisted sperm analysis in rat. Annual Report of Shiongi Research Laboratories, 53: 1-20.

32.Sakr SA, Mahran HA, Abo-El-Yazid SM (2011): Effect of fenugreek seeds extract on cyclophosphamide-induced histomorphometrical, ultra-structural and biochemical changes in testes of albino mice. Toxicology and Industrial Health, 28(3): 276-288.

33. Kumar V, Abbas AK, Aster JC et al. (2013): basic pathology. 9th ed. Philadelphia, PA: Saunders, Elsevier. https://www.elsevier.com/books/robbins-basicpathology/kumar/978-1-4377-1781-5

34. Elharoun H, Bashandy MA (2014): Testicular toxic effect of Di-N-Butylphthalate on adult male albino rat and the possible protective role of Vitamin C \& E (ultrastructural, histological and histochemical study). J Am Sci., 10:147157.

35. Aguilar-Mahecha A, Hales B, Robaire B (2005): Effects of acute and chronic cyclophosphamide treatment on meiotic progression and the induction of DNA double strand breaks in rat spermatocyte. Boil Reprod., 72:1297-1304.

36. El-Beltagi E, Elwan W, Abdel Mohsen N et al. (2017): Histological and immunohistochemical study on the effect of gibberellic acid on the seminiferous tubules of testis of adult albino rat and the possible protective role of grape seeds proanthocyanidin extract. Tanta Medical Journal, 45 (2):7991.

37. Badr El-Din S, Abd-El Aty OA (2012): Biochemical and immunocytochemical studies of the testicular changes after treatment with duloxetine hydrochloride and the possible protective effects of omega 3 in adult rat model of depression. AAMJ., 10(3): 1-7.

38. Haubitz M (2007): Acute and long- term toxicity of cyclophosphamide. Transplantations Medizin/, 19: 26-31.

39. Tamura S, Kono T, Harada $C$ et al. (2009): Estimation and characterisation of major royal jelly proteins obtained from the honeybee Apismerifera. Food Chem., 114:1491-1497.

40. Banudevi S, Krishnamoorthy G, Venkataraman $P$ et al. (2006): Role of alpha-tocopherol on antioxidant status in liver, lung and kidney of PCB exposed male albino rats. Food Chem. Toxicol., 44 (12):2040-2046.

41.Sahoo D, Roy A, Chainy G (2008): Protective effect of vitamin $\mathrm{E}$ and curcum on L- thyroxin-induced rat testicular oxidative stress. Hem Biol Interact., 176(2-3): 121-128.

42.Arora PD, Glogauer M, Kapus A et al. (2004): Gelsolin mediates collagen phagocytosis through a rac-dependent step. Mol Biol Cell, 15(2): 588-599.

43. Tripathi DN, Jena GB (2008): Astaxanthin inhibits cytotoxic and genotoxic effects of cyclophosphamide in mice germ cells. Toxicology, 248:96-103.

44. Sabik L, Abd El-Rahman S (2009): Alpha-tocopherol and ginger are protective on cyclophosphamide-induced gonadal toxicity in adult male albino rats. Basic and App Pathol., 2:21-29. 